\title{
VALORES, VERdAdE E INVESTIGAÇÃO: UMA ALTERNATIVA PRAGMATISTA AO NÁO COGNITIVISMO DE RUSSELL
}

\author{
Ivan Ferreira da Cunha ${ }^{1}$
}

Resumo: Este artigo apresenta um referencial pragmatista para compreender o estatuto epistêmico da valoração que é produzida na reflexão acerca das consequências sociais de propostas científicas e tecnológicas. O problema é posto, seguindo-se as consideraçôes de Bertrand Russell sobre o impacto da ciência na sociedade. Russell argumenta que a valoração de arranjos sociais fica fora dos limites do conhecimento, porque valoraçóes não podem ser verdadeiras ou falsas, em sentido correspondencial. Isso leva o pensamento social a um impasse, pois náo se pode saber que dado arranjo social seria indesejável ou inadequado. Este texto esboça uma alternativa, a partir dos trabalhos sobre valoração de Clarence Irving Lewis, tomados em continuidade com a teoria da investigaçáo de John Dewey. Esse referencial alternativo assume noçóes epistêmicas de verdade e justificaçáo, o que permite que valoraçóes possam ser concebidas em contextos de investigaçáo e, assim, como objetos de conhecimento.

Palavras-chave: Epistemologia. Filosofia social. Distopia. Russell. Pragmatismo.

\section{INTRODUÇÃo}

Quando refletimos sobre o impacto que um avanço científico e tecnológico terá na sociedade, geralmente extraímos uma conclusão valorativa, de que referido avanço será benéfico ou prejudicial, que resolverá algum problema ou que causará certas dificuldades. Este artigo tem como objetivo discutir o estatuto epistêmico desse tipo de conclusão valorativa, o qual parece acompanhar grande parte, não somente das inovaçóes tecnológicas, mas também das propostas das ciências sociais para intervenção em problemas concretos, o que pode ser compreendido como tecnologia social. Para essa discussão, este trabalho partirá das consideraçóes de Bertrand Russell sobre o impacto da ciência na sociedade, as quais projetam um futuro distópico.

\footnotetext{
${ }^{1}$ Docente no Departamento de Filosofia e membro do Núcleo de Epistemologia e Lógica - NEL - da Universidade Federal de Santa Catarina - UFSC, Florianópolis, SC - Brasil. (D) https://orcid. org/0000-0002-2060-2493 E-mail: ivan.fc@ufsc.br
}

http://doi.org/10.1590/0101-3173.2020.v43n3.17.p245

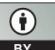

This is an open-access article distributed under the terms of the Creative Commons Attribution License. 
No entanto, notaremos, que Russell assume uma postura não cognitivista sobre valores, a qual, como argumentaremos, parece problemática para a discussão que desenvolvemos, por negligenciar algumas intuiçóes comuns que temos a respeito da valoração. Para lidar com o problema, este texto trará uma alternativa pragmatista construída principalmente a partir da obra de Clarence Irving Lewis e de John Dewey. Não é nosso interesse aqui estabelecer uma conciliação entre as propostas de Russell e o pragmatismo americano; tampouco buscamos fixar uma perspectiva pragmatista consistente: sabemos que há diferenças entre os diversos autores dessa tradição, de modo que tomaremos livremente aspectos de Lewis e Dewey, a fim de esboçar uma solução ao problema da valoração de avanços tecnológicos e científicos, especialmente no que diz respeito ao impacto de tais avanços na sociedade.

\section{A distopia de Russell}

Em The Scientific Outlook, Russell apresenta alguns avanços científicos já alcançados em sua época e algumas indicaçóes sobre avanços técnicos que a ciência pode vir a obter. Ele discute, por exemplo, técnicas de irrigação e de produção de alimentos, a manipulação genética e o desenvolvimento de medicamentos psicoativos, bem como o avanço dos meios de comunicação em massa. Na parte final do livro, Russell faz algumas especulaçóes sobre a maneira pela qual a sociedade poderia ser transformada pelos avanços científicos que ele imagina. Assim, ele prevê o surgimento de uma oligarquia de detentores da técnica científica. Os interesses dessa oligarquia, especula Russell, moldariam a sociedade de sorte a produzir pela engenharia genética castas de trabalhadores perfeitamente adaptados às funções que vão desempenhar. Russell nota, ainda, que medicamentos e técnicas psicológicas podem ser usados para produzir um contentamento geral, ao mesmo tempo em que técnicas de comunicação garantem a censura de qualquer intenção desviante (RUSSELL 2009).

É interessante observar que muitas das transformaçôes sociais imaginadas por Russell aparecem no bastante conhecido romance Admirável Mundo Novo, de Aldous Huxley (2014), publicado no ano seguinte. ${ }^{2}$ Huxley

\footnotetext{
${ }^{2}$ Russell comenta, no prefácio à segunda edição, que as ideias da parte final de seu livro foram popularizadas por dois livros, Admirável Mundo Novo, de Huxley, e Managerial Revolution, de James Burnham. Russell não deseja sugerir que tenha influenciado esses livros, mas espera que o paralelo entre as obras sirva para "persuadir o leitor de que [seus] temores são mais do que uma fantasia individual" (RUSSELL, 2009, p. xxii). Faço uma apresentação do caráter utópico e distópico do livro de Huxley, a partir da perspectiva da filosofia da ciência, em Cunha (2015).
} 
usa a forma literária para apresentar uma distopia: um arranjo social que é visto por seus proponentes e defensores como uma utopia, a sociedade perfeita, onde todos são felizes o tempo todo; mas os personagens principais, que personificam o ponto de vista do autor (e do leitor) do livro, veem tal arranjo social como o contrário de uma utopia.

Já Russell defende mais diretamente que, na civilização científica, para que esta seja uma boa civilização, "[...] é necessário que um aumento em conhecimento seja acompanhado por um aumento em sabedoria. [Russell entende] por sabedoria uma concepçáo correta sobre os fins da vida" (RUSSELL 2009, p. xxv). Então, o texto de Russell (2009, p. xxv) apresenta a posição com a qual vamos nos ocupar neste artigo: "Isto [a sabedoria, ou a concepção correta sobre os fins da vida] é algo que a ciência em si mesma não fornece".

Esse ponto de vista de Russell coloca enunciados avaliativos, como o de que a sociedade organizada de maneira científica é boa ou ruim, fora do domínio do conhecimento; por essa razão, esse posicionamento pode ser considerado uma espécie de náo cognitivismo sobre valores. ${ }^{3} \mathrm{Na}$ época de Russell, o não cognitivismo era uma posição comum, tendo sido adotada por positivistas lógicos, como Alfred J. Ayer (2001) e Rudolf Carnap (1934), em diferentes formas. A proposta central é que a ciência não pode determinar os fins que devem ser perseguidos, assim como não pode dizer que determinado fim é bom, adequado, agradável, justo, ou que certo arranjo social seria desagradável, distópico. Já a busca de meios para obter certos fins e a derivação de consequências desses fins estariam dentro do escopo da ciência. No exemplo que temos utilizado, a ciência é capaz de dizer se a manipulação genética tem condiçôes de ser usada para tornar as pessoas mais aptas a certos tipos de trabalho; a ciência pode também afirmar que esse uso pode desencadear uma sociedade dividida por castas, com todas as consequências que uma tal divisão pode ter. Mas estaria fora do alcance da ciência dizer que esse resultado seria ruim, indesejável ou distópico.

Essa concepção tem como base a distinção entre fatos e valores. A ciência supostamente deve se ocupar do domínio dos fatos, os quais são objetivos e acessíveis a qualquer um de nós, se receber certa instrução,

\footnotetext{
${ }^{3}$ Há diversas formas de não cognitivismo, bem como de cognitivismo, a posição oposta. Van Roojen (2018) faz uma boa apresentação desses posicionamentos. A discussão entre essas duas famílias de pontos de vista é bastante comum, na metaética, contudo, não tratarei de detalhes dessa discussão neste texto.
} 
independentemente de nossos desejos e inclinaçôes. Já os valores seriam o domínio da subjetividade - à exceção de alguns casos extremos, um grupo de pessoas não conseguiria chegar a um consenso sobre se certa configuração seria boa ou ruim: isso seria uma questão de inclinação pessoal. Russell traz à nossa atenção que, naquele início de século XX, a ciência não era praticada como uma busca pela verdade, mas como "[...] uma técnica para a transformação de nós mesmos e de nosso ambiente" (RUSSELL 2009, p. 198). O problema que preocupa Russell é que a busca pela verdade é um daqueles casos extremos de valoração, pois é um fim a respeito do qual (praticamente) todas as pessoas concordam que é benéfico. Já a busca pelo poder, que caracteriza a técnica científica, ressalta Russell (2009, p. 199), “[...] não é uma das finalidades da vida, mas meramente um meio para outros fins, e até que as pessoas se lembrem das finalidades às quais o poder deve ser submisso, a ciência não fará o que pode para contribuir à boa vida”.

Mas, perguntamos então, quais são essas finalidades? A resposta é que Russell (2009, p. 199) náo pensa "[...] que uma pessoa tenha o direito de legislar sobre outra neste assunto. Para cada indivíduo, as finalidades da vida são aquelas coisas que ele deseja profundamente e que, se existissem, lhe dariam paz". Isto é, as conclusóes de cada pessoa sobre quais são as coisas boas da vida servem apenas para a pessoa que as alcançou. $\mathrm{O}$ máximo que podemos fazer com as nossas próprias conclusóes é aconselhar nossos pares - e o conselho de cientistas ou de filósofos que dedicaram muito tempo a meditar sobre alguma questão não vale mais que o de qualquer outra pessoa, afinal, este é o domínio da subjetividade. O mais longe que a argumentação de Russell (2009, p. 200) consegue chegar é para assinalar que

[...] a esfera dos valores está fora da ciência, exceto em que a ciência consiste na busca por conhecimento. A ciência como busca por poder não deve se impor sobre a esfera dos valores, e a técnica científica, se almeja enriquecer a vida humana, não deve ter mais importância que as finalidades a que deve servir.

Para além disso, Russell só poderia nos oferecer sua opinião, a qual não pode ser caracterizada como conhecimento, visto que não possui qualquer justificação científica.

No entanto, isso nos traz uma sensação estranha: depois de ler The Scientific Outlook e Admirável Mundo Novo, temos a sensação de ter adquirido conhecimento sobre certos arranjos sociais, os quais, embora agradáveis em 
muitos aspectos, seriam em geral indesejáveis - e poderíamos incluir nessa lista outras distopias do século XX, como 1984 (ORWELL, 2000), Nós (ZAMYATIN, 2017) e Os Despossuidos (LE GUIN, 2017). Os autores desses textos dedicaram uma boa porção de seu tempo a pensar sobre as consequências sociais de certos avanços científicos e tecnológicos e, assim, parecem ter obtido algum tipo de conhecimento. E as obras que eles produziram têm o potencial de conduzir seus leitores a obter conhecimento parecido. Quando encontramos alguém que, como nós, leu Admirável Mundo Novo e conversamos a respeito do livro, geralmente concordamos que alguns aspectos da sociedade descrita são interessantes: a ausência de doenças e crimes, o emprego garantido, a liberdade sexual, o acesso irrestrito a entorpecentes que não têm efeitos colaterais, por exemplo; e geralmente concordamos também que os aspectos negativos, como a desigualdade social, a repressão de sentimentos e a estagnação cultural resultante da ausência de arte e de filosofia, tornam aquela sociedade largamente indesejável.

Charles Pigden (2003) aponta que o próprio Russell sofreu com esse impasse. Ele gostaria, naturalmente, que suas reflexôes sobre os fins da ciência, sobre a educação (RUSSELL, 2010) e sobre o casamento (RUSSELL, 1970), por exemplo, fossem ouvidas pelas pessoas e que suas propostas fossem postas em prática. E, para tanto, não haveria argumento melhor do que se Russell pudesse dizer que ele sabia que a adoção de suas propostas para a educação e para a organização da vida privada, enrte outras, conduziria a uma sociedade melhor. Se Russell pudesse atribuir conhecimento a suas reflexóes, seus leitores poderiam, entâo, se julgar justificados a acreditar que os arranjos sociais propostos são melhores - seus leitores poderiam também saber que a sociedade seria melhor, se fosse organizada de tal e tal modo. Estaríamos diante de conhecimento por descrição, entretanto, ainda assim, conhecimento. E, da mesma forma, gostaríamos de poder saber que são ruins as consequências de uma sociedade segregada em castas baseadas na engenharia genética, como aquelas descritas em The Scientific Outlook. Em outras palavras, gostaríamos que a filosofia social de Russell tivesse alguma justificação para além da própria autoridade do Terceiro Conde Russell.

Em suma, é certo que temos uma intuição ou noção comum de que nossas reflexôes sobre valores constituem conhecimento. No entanto, Russell não poderia considerar que o que acabo de descrever seja conhecimento. A razão disso é que Russell assume um compromisso fundamental com a concepção correspondencial da verdade - e, como sabemos, a verdade é 
uma das condiçôes necessárias para o conhecimento. Em outras palavras, para Russell, a pretensão de conhecimento que apresentei acima não pode se concretizar, não podemos considerar tais declaraçôes como conhecimento, porque elas não poderiam ser verdadeiras em um sentido correspondencial. Essa incompatibilidade entre a valoração e a verdade aparece mais claramente quando Russell revisita o tema da relação entre ciência e valores, duas décadas mais tarde.

\section{A CRÍtica AO PRAGMATISMO}

Em The Impact of Science on Society, publicado em 1952, Russell apresenta uma crítica ao pragmatismo de John Dewey. Ele diz que tal filosofia concebe a ciência como uma busca não por afirmaçóes verdadeiras, mas por instrumentos que funcionam. Nas palavras de Russell (1985, p. 93), para Dewey,

[...] como qualquer outro instrumento, [uma teoria científica] é julgada boa ou ruim por sua eficiência [...], e como qualquer outro instrumento, ela é boa em um momento e ruim em outro. Enquanto for boa, [uma teoria científica] pode ser chamada 'verdadeira', mas a essa palavra não devem ser permitidas as conotaçóes usuais. Dewey prefere a expressão 'assertabilidade garantida' à palavra 'verdade'.

Ou seja, Russell vê o pragmatismo de Dewey como associado a uma concepçáo da ciência como técnica. Ao invés de uma busca pela verdade, Dewey concebe a ciência como uma busca pela eficiência na transformaçáo do mundo à nossa volta.

O problema que Russell encontra, nessa concepção, é que ela parece permitir que a verdade seja determinada e modificada por quem quer que detenha o poder, independentemente dos fatos. ${ }^{4}$ No exemplo provocativo de Russell (1985, p. 92), “[...] em 1920 era 'verdadeiro' que Trotsky desempenhou um importante papel na Revolução Russa; em 1930 isso era 'falso'”. Isto é, um governo autoritário e poderoso - como o da União Soviética - pode manipular nosso acesso à informação e forçar-nos a modificar nossas crenças. Assim, no caso mencionado, para evitar perseguição, uma pessoa que acreditava que

\footnotetext{
${ }^{4}$ Russell apresenta essa crítica ao pragmatismo em diversas oportunidades, desde os ensaios do início de sua carreira (cf. RUSSELL, 1994) até textos populares, tais como os capítulos 29 e 30, respectivamente sobre William James e John Dewey, do Volume 3 de sua História da Filosofia Ocidental (RUSSELL, 2015).
} 
Trotsky tinha participado da Revolução Russa precisou mudar de opinião e passar a crer na falsidade daquela afirmação, no final da década de 1920, quando o governo soviético exilou Trotsky e passou a perseguir e aprisionar seus aliados. Em uma famosa colocação de Russell (1985, p. 94), “[...] se você controla a polícia, [a teoria pragmatista] lhe dá o poder divino de fazer verdade. Você não pode tornar frio o sol, mas você pode conferir 'verdade' pragmática à proposição 'o sol é frio' se você puder assegurar que todos os que a negam sejam liquidados."

O correspondentismo adotado por Russell contorna esse problema. A verdade, segundo essa concepção, é estabelecida na correspondência entre uma crença, ou uma proposição, e um fato ou um complexo de fatos. Com isso, a verdade é uma relação entre um elemento humano - seja um fenômeno psicológico, como a crença, seja um fenômeno linguístico - e um elemento metafísico, um aspecto da realidade que limita o poder humano. Em mais um exemplo de Russell (1985, p. 94), “[...] se você diz que 'o Polo Sul é frio', você diz algo que [...] é 'verdadeiro' em virtude de um 'fato', a saber, que o Polo Sul é frio. E isso é um fato, náo porque pessoas acreditam nisso ou porque vale a pena acreditar nisso; simplesmente é um fato." Dessa forma, para além do que desejamos ou tememos, para além do que consideramos bom ou ruim, agradável ou desagradável, existem os fatos que constituem a realidade. E nossas crenças ou declarações serão verdadeiras, se corresponderem aos fatos; se não corresponderem, serão falsas. ${ }^{5}$

Esse ponto de vista traça uma distinção bastante clara entre sujeito e objeto: as crenças são subjetivas, mas os fatos são objetivos; o conhecimento é dotado de objetividade, porque tem como um de seus constituintes a verdade, isto é, a correspondência com os fatos. Já as valorações são meramente subjetivas: se eu acredito que seria desagradável viver numa sociedade como aquela descrita em Admirável Mundo Novo e você discorda de mim, negando que haja aspectos desagradáveis (ou distópicos) naquela sociedade, não existe um fato objetivo ao qual possamos recorrer, para resolver nossa disputa. Chegaremos a um impasse no qual eu digo que aquele arranjo é desagradável para mim e você diz que é agradável para você. Se eu disser que minha valoração concorda com aquela assumida por Russell, você terá todo o direito de rejeitar esse argumento, pois é mero recurso à autoridade.

\footnotetext{
${ }^{5}$ Há diversos problemas com o correspondentismo; de particular relevância é o problema de especificar o que exatamente é essa relaçáo de correspondência. Haack (2002) e Dutra (2001) discutem esse e outros problemas em profundidade. A exposiçấo mais completa do correspondentismo russelliano pode ser encontrada em Russell (1998).
} 
A teoria correspondencial da verdade, conforme defende Russell, parece se aproximar de nossas noçóes comuns. Porém, isso parece entrar em conflito com aquela outra noção comum que apontei, na seção anterior, de que temos a sensação de adquirir algum conhecimento sobre quais arranjos sociais são agradáveis ou desagradáveis, quando temos contato com utopias e distopias. No restante deste texto, farei uma análise dessa sensação de conhecimento e esboçarei uma tentativa de defender que podemos atribuir conhecimento a esse tipo de valoração. Para tanto, minha argumentação será baseada justamente no pragmatismo que Russell tanto criticou.

\section{VaLORAÇÃo E INVESTIGAÇÃo}

Em An Analysis of Knowledge and Valuation, o pragmatista americano C. I. Lewis apresenta uma alternativa ao não cognitivismo. A proposta fundamental é que consideremos três tipos de valoraçôes, isto é, três tipos de atribuição de valores a objetos ou situaçôes. Em primeiro lugar, podemos falar de valoração na forma de um "enunciado expressivo de uma qualidade de valor encontrada no diretamente vivenciado" (LEWIS, 1946, p. 374). Trata-se da percepção pessoal de uma qualidade valorativa, como agradável ou desagradável, quando temos certa experiência. Por exemplo, em uma tarde gélida de inverno, a sensação do calor do sol pode ser percebida como agradável por uma pessoa que está fazendo uma caminhada. Temos, nesse caso, uma percepção sensorial, associada à mudança de temperatura, e que é avaliada como agradável pela pessoa que tem essa experiência. Esse tipo de avaliação, destaca Lewis, é sempre verdadeiro, pois diz respeito a algo que é percebido diretamente por uma pessoa. É uma percepção análoga à da visão de certa cor: quando uma pessoa diz "vejo aqui a cor vermelha", não temos condiçóes de duvidar da veracidade dessa percepção; podemos considerar se a pessoa em questão está tendo uma alucinação ou se é vítima de uma ilusão de óptica, mas não do fato de que a pessoa percebe a cor vermelha naquele momento. Da mesma forma, se a pessoa diz "considero essa sensação agradável", estamos diante de uma atribuição de valor a um elemento perceptivo - e náo temos motivo para negar que a pessoa esteja tendo uma tal percepção.

No entanto, a veracidade da valoração da experiência direta é completamente subjetiva. Se eu e você caminhamos juntos em uma tarde fria e sentimos o calor do sol, não haverá contradição se eu considerar essa sensação agradável e você considerá-la desagradável. A valoração nesses casos concerne 
à experiência subjetiva de cada pessoa e será sempre verdadeira em relaçáo àquela experiência subjetiva. Lewis (1946, p.375) enfatiza que

[...] qualquer tal formulação ou relato de valor aparente, tomado por si mesmo e despido de toda implicação ulterior, é um enunciado expressivo, autoverificável [...] e que não está sujeito a erro, exceto mero erro linguístico nas palavras escolhidas para expressá-lo.

Podemos atribuir falsidade a uma afirmação dessas, assim como no caso da percepção de uma cor, apenas porque sabemos que é possível mentir ou sofrer engano a respeito de nossas experiências pessoais.

Assim, Lewis estabelece um elemento básico para a valoração: a percepção de qualidades valorativas na experiência direta. ${ }^{6}$ Esse elemento básico não constitui propriamente conhecimento, por se tratar de simples percepção subjetiva, que, por si só, não poderia ser submetida a nenhum processo de validação, verificação ou justificação. Quando envolve esses processos, como veremos, a valoração é classificada por Lewis nos outros dois tipos.

O segundo tipo de atribuição de valor é aquele em que fazemos uma "[...] predição [...] do possível acréscimo de qualidade valorativa na experiência - por exemplo, de prazer ou de dor - condicionado à adoção de um modo particular de ação" (LEWIS, 1946, p. 375). Em outras palavras, somos capazes de fazer prediçóes de que, se agirmos de certa maneira, teremos a percepçáo de determinadas qualidades valorativas, ou seja, teremos uma valoração do primeiro tipo. Esse segundo tipo de valoração é o levantamento de regularidades sobre experiências de valoração. Um dos exemplos de Lewis é de quando vemos um pedaço de ferro aquecido, a ponto de se tornar vermelho, e fazemos a predição de que tocá-lo será desagradável, de que sentiremos dor, se fizermos isso. Sendo uma predição confirmável ou verificável, esse tipo de valoração pode figurar como conhecimento. A verificação, nesse caso, seria efetivada com a ocorrência de uma valoraçáo do primeiro tipo que estivesse em concordância com o que foi previsto, todavia, a simples possibilidade

\footnotetext{
${ }^{6}$ Deve-se notar que Lewis adota o conceito pragmatista de experiência como um estofo ontológico, o chamado monismo neutro, o qual encontramos nas obras de John Dewey (1958) e de William James (2003). Assim, sua proposta recorre com frequência à noção de fluxo da experiência (cf. LEWIS, 1946, 1956); esse primeiro tipo de valoração é uma atribuiçấo de valor a um trecho do fluxo de experiência. É interessante observar que Russell também adota uma versão do monismo neutro de James, em algumas de suas obras (cf. RUSSELL, 1992, 2007). Para os fins de nossa argumentação no presente texto, não precisamos nos aprofundar a respeito dessa questão.
} 
determinada de ocorrência de uma tal experiência já permite que consideremos essa predição como candidata a conhecimento. ${ }^{7}$

Esse tipo de predição ainda está no domínio da subjetividade, pois, nos casos bem-sucedidos, ela geralmente concerne à própria experiência do sujeito que faz a predição. É possível também fazer prediçóes a respeito de outras pessoas, mas isso depende de termos informação sobre as experiências valorativas de primeiro tipo dessas outras pessoas - e a própria verificação dependeria de um testemunho da pessoa em questão. No caso do exemplo do ferro quente, podemos supor que outras pessoas têm seus sistemas nervosos organizados de maneira semelhante à nossa, que sentiriam dor de modo semelhante e atribuiriam valor semelhante à experiência - mas sabemos que há pessoas que se dedicam a certas formas de arte por modificação corporal e que valoram diferentemente a experiência da dor em queimaduras desse tipo. Isto é, essas prediçóes do segundo tipo adquirem um grau mais elevado de possibilidade de verificação, quanto mais próximos estivermos da experiência de primeiro tipo que a verificaria. Podemos argumentar que essas prediçôes são idiossincráticas e o suposto conhecimento que elas podem produzir se refere às expectativas de uma pessoa acerca de seus próprios valores - ou seja, quando acertadas, prediçóes desse tipo indicam conhecimento sobre os interesses e gostos da pessoa a quem se diz respeito.

O terceiro tipo de valoração é o que Lewis (1946, p. 375) chama de "atribuiçấo da propriedade objetiva de ser valioso a um existente ou possível existente". Esse é o tipo de valoração que Lewis considera mais importante, e é também o que mais nos interessa, neste texto, pois é a afirmação de que determinado objeto apresenta certo valor.

Um dos exemplos dados por Lewis é da afirmação de que meu vizinho é um bom músico. O sentido desse enunciado vai além das simples percepçóes imediatas de valor: posso considerar que meu vizinho é um bom músico, “[...] embora a seleção em que ele está trabalhando atualmente não me deixe impressionado, ou mesmo se eu achar que sua persistente exibição de virtuosismo é irritante por interromper minha linha de raciocínio" (LEWIS, 1946, p.376-367). Assim, quando digo que meu vizinho é um bom músico, não estou simplesmente fazendo a predição de que terei sensaçóes agradáveis, na próxima vez em que ouvi-lo tocar ou em todas as vezes em que os sons de seu instrumento chegam aos meus ouvidos. Mais do que isso, quando

${ }^{7}$ A possibilidade de verificação potencial, isto é, em casos em que ela não se realizará, é discutida em Lewis (1970). 
atribuo aquele valor ao meu vizinho, estou atribuindo a ele a qualidade de gerar experiências valorativas do primeiro tipo e também de gerar prediçóes do segundo tipo, porém, não espero encontrar uma verificação completa: essa atribuição almeja uma objetividade, a qualidade atribuida àquele objeto de gerar valoraçôes de maneira contínua, indefinidamente. Para Lewis (1946, p.377-8), o significado de uma valoração desse terceiro tipo é

[...] traduzível em uma multiplicidade de juízos [do segundo tipo], cada um por si mesmo decisivamente verificável ou falseável, e cada um representando uma possível confirmação desse juízo objetivo. Uma tal afirmação de valor objetivo terá alguma probabilidade ou improbabilidade [...], e essa probabilidade pode aumentar ou diminuir indefinidamente pelo teste de suas confirmações. Porém, sempre restará uma significância ulterior e ainda náo testada, pois o número de tais confirmações possíveis não será finitamente exaurível.

Isso quer dizer que as atribuiçôes de valor, para Lewis, são como as hipóteses das ciências naturais, em que se pretende alcançar certo grau (relativamente elevado) de necessidade e universalidade. Dessa forma, afirmar que meu vizinho é um bom músico é parecido com afirmar que todos os corvos são pretos: isso significa que, quando um corvo é mencionado, criamos a expectativa de que sua plumagem seja preta, expectativa que provavelmente se confirmará em nossa experiência futura. Assim, se convido você para irmos ao zoológico ou à Torre de Londres ou a um parque urbano no Hemisfério Norte, para vermos os corvos, isso gerará a predição de que veremos pássaros da cor preta em nosso passeio. Se efetivamente fizermos o passeio e se efetivamente virmos os corvos, então teremos experiências pessoais, subjetivas e individuais, de percepção da cor preta naqueles objetos. Similarmente, se formos a uma apresentação musical de meu vizinho, você - sabendo que meu vizinho é valorado como um bom músico - criará a expectativa de uma boa performance, de uma peça bem executada.

A verificação dessa expectativa não depende necessariamente de gosto, mas de uma habilidade para apreciar música, identificando as situaçóes nas quais podemos assegurar que se trata de um bom músico, mesmo quando a composição executada não é de nosso agrado. Uma situaçáo parecida ocorre no caso dos corvos, em que a verificação de "todos os corvos são pretos" envolve que saibamos identificar um corvo - e não confundi-los com gralhas, por exemplo - e que tenhamos domínio dos conceitos relacionados à cor preta. 
Nos dois casos, ainda, podem ocorrer algumas situaçóes que comprometem a universalidade e a necessidade das afirmaçóes. Poderíamos dizer, por exemplo, que meu vizinho nem sempre foi um bom músico; ou ainda que, às vezes, ele não faz um boa performance. Todavia, isso não nos impediria de dizer que meu vizinho é um bom músico - talvez façamos alguma qualificação adverbial como "geralmente" ou "atualmente". Da mesma maneira, podemos dizer que todos os corvos são pretos, mesmo sabendo que um dia houve corvos malhados, hoje extintos, e que há corvos albinos, embora bastante raros. Esses casos não mudam a nossa expectativa de encontrar animais pretos, quando predizemos a presença de corvos - bem como não mudamos nossa expectativa de presenciar uma boa performance, quando nos preparamos para assistir à apresentação de um bom músico.

A valoração de meu vizinho como um bom músico gera prediçóes de que presenciaremos execuçóes impecáveis; no entanto, isso é diferente das prediçôes de que teremos experiências agradáveis, ao assistir à apresentação. Essas prediçóes de experiências agradáveis parecem ser igualmente geradas pela valoração objetiva, aquela do terceiro tipo, e elas são bem mais difíceis de se verificar, pois dependem de gosto e de inclinaçóes pessoais.

Neste ponto, parece que temos o mesmo problema que apontamos acima: a afirmação de que a sociedade de Admirável Mundo Novo é desagradável ou indesejável parece depender de inclinaçôes pessoais, um grau de subjetividade que não temos, quando falamos da cor preta dos corvos. Discutiremos isso mais adiante. Por enquanto, devemos ressaltar que, para Lewis (1946, p. 372), isso não é motivo para desqualificar o potencial veritativo da valoração:

[...] alguém que sabe, por exemplo, que gosta de Bach e que tem aversão a Stravinsky pode ser considerado táo ignorante musical quanto se queira, mas quando ele olha o programa do concerto, ele sabe o que esperar. Sua predicação de valor tem um conteúdo verificável e possui significância genuinamente cognitiva.

O problema, como vimos, é que, na perspectiva adotada por Russell, não podemos atribuir verdade a esses casos, porque não há estados de coisas, fatos objetivos, aos quais correspondem afirmações tais como "meu vizinho é um bom músico" ou mesmo "será agradável ir ao concerto". Essas afirmaçóes só poderiam corresponder a estados subjetivos, relativos às pessoas que as proferem. A fim de construir uma resposta a esse problema, apresentarei uma 
perspectiva pragmatista para o conhecimento e a verdade, considerando tais noçôes como dependentes de um procedimento de investigação.

\subsection{TeOria Da InVESTIGAÇáo}

A estratégia de tomar o conhecimento como relacionado à investigação tem origem nos trabalhos de Charles Sanders Peirce e recebeu um desenvolvimento bastante profundo na obra de Dewey, na primeira metade do século XX; a apresentação que farei seguirá esse autor. É preciso ressaltar que Lewis não discute de maneira explícita uma teoria da investigação, mas é possível dizer que essa estratégia é compatível com suas propostas (cf. ROSENTHAL, 2007). Na verdade, Lewis adota o princípio pragmatista de que não há uma separação rígida entre saber e fazer, entre pensar e agir e entre metas cognitivas e fins práticos (cf. SÁNCHEZ GARCÍA, 2017). E, como veremos, essa ideia central da filosofia americana também norteia a concepção de investigação.

De modo fundamental, podemos considerar que uma investigação é um procedimento que conduz o investigador a sair de uma situação indeterminada de dúvida e chegar a uma determinação. A dúvida, como concebe Peirce (1992, p. 114), é uma condição irritante que nos causa um esforço para resolvê-la - trata-se de uma situação na qual um agente não vê um curso de ação definido. A situação oposta, em que há um curso de ação determinado, dessa forma, é o que se chama de crença. O objetivo da investigação, logo, é sair da situação indeterminada em que a ação é interrompida e estabelecer uma crença, isto é, um fluxo de ação determinado. É importante notar que a dúvida é, nessa perspectiva, uma condição orgânica da interação de um agente com seu ambiente. Para mudar a situação, ou seja, para sair da dúvida, é necessário mudar a forma de interação com o ambiente. E, assim, como nos explica Dewey (2008, p. 111),

[...] a interação orgânica se torna investigação quando consequências existenciais são antecipadas; quando condiçóes ambientais são examinadas com referência a suas potencialidades; e quando açóes de resposta são selecionadas e ordenadas com referência à atualização de algumas das potencialidades, em detrimento de outras, em uma situaçáo existencial final. 
Em outras palavras, uma situação indeterminada de dúvida começa a ser determinada em direção a uma crença, quando certas interações com o ambiente são projetadas e certas operaçôes são realizadas. Nesse sentido, a primeira etapa para sair de uma situação irritante de dúvida é a formulação de um problema. É importante diferenciar a dúvida do problema, pois formular um problema envolve a percepção de que uma situação indeterminada é complicada o bastante para precisar de uma investigação. Ao formular o problema, um agente já está identificando causas, motivos e outras relaçóes entre os componentes da indeterminação de sua situação. Além disso, e principalmente, a formulação do problema coloca a situação em um contexto no qual se podem conceber soluçôes:

Sem um problema, há um tatear no escuro. A maneira pela qual o problema é concebido decide quais sugestôes específicas são cogitadas e quais são dispensadas; quais dados são selecionados e quais rejeitados; é o critério de relevância e irrelevância de hipóteses e estruturas conceituais (DEWEY, 2008, p. 112).

Ou seja, somente na formulação de um problema é que obtemos um contexto no qual poderemos antecipar consequências de certas açóes face à situação indeterminada e avaliar as potencialidades dessas açôes. Isto é, formular o problema é o primeiro estágio na compreensão da situação de dúvida - e apenas com essa compreensão é que podemos inventar e considerar hipóteses, bem como raciocinar a respeito dessas hipóteses, para determinar um curso de ação. Portanto, se a formulação de um problema é o primeiro passo em direção à determinação de uma situação de dúvida, o segundo passo é a elaboração de hipóteses.

No contexto da investigação, as hipóteses são elaboradas ou sugeridas em resposta ao problema que foi formulado. Elas são estratégias de ação, por meio das quais a situação de dúvida poderá ser determinada na forma de uma crença. Com isso, notamos que afirmaçóes tais como "meu vizinho é um bom músico" devem ser tomadas como sugestóes de expectativas que podemos criar em resposta a problemas que foram formulados em situaçóes de dúvida - o mesmo ocorre com "todos os corvos são pretos", mas tratarei disso na próxima seção. Em outros termos, a abordagem pragmatista oferece uma crítica à abordagem analítica tradicional de tomar essas hipóteses como afirmaçóes descontextualizadas: ao considerar as hipóteses fora do contexto do problema 
em que são formuladas, perdemos de vista a possibilidade de compreender seu sentido de uso, seu sentido pragmático. ${ }^{8}$

Por isso, uma afirmação valorativa com pretensão de objetividade, como "meu vizinho é um bom músico", só tem sentido se concebida como indicação de uma estratégia de ação para resolver um problema. No exemplo que apresentei acima, diante do meu convite para assistir ao recital de meu vizinho, a sua indecisão, a respeito de ir ou não, é colocada como um problema formulado em resposta à situação indeterminada, à dúvida diante do meu convite. A situação indeterminada, nesse caso, é caracterizada como a ansiedade hesitante que resulta de ter que dar uma resposta. A formulação do problema envolve considerar as condições pelas quais tal situação pode ser determinada: pensemos, por exemplo, que o recital acontecerá em um teatro próximo à sua casa e que o ingresso é gratuito; isso permite que o problema seja formulado sem que tenhamos que levar em conta as dificuldades de deslocamento e o preço do ingresso. Os cursos de ação possíveis, então, podem ser simplificados em ir ao recital ou não ir ao recital. A hipótese valorativa que apresentei, "meu vizinho é um bom músico", conduzirá a uma determinação da sua situação, dependendo se você aceitará ou não a hipótese. Aqui já estamos em outro estágio da investigação.

A operação de considerar se a hipótese sugerida é adequada é chamada por Dewey de raciocínio ou argumentação (reasoning). Trata-se do processo de desenvolver a hipótese em relação aos termos do problema e aos resultados já consolidados de outras investigaçóes, com o objetivo de examinar a adequação da hipótese ao contexto de investigação. Assim, busca-se notar relaçôes do significado operacional da hipótese em questão, como ressalta Dewey (2008, p. 115), “[...] em relação a outros significados no sistema do qual [a hipótese] é integrante [...]. Se tal e tal relação de significados é aceita, entấo estamos comprometidos a tais e tais outras relaçóes de significados, pois elas integram o mesmo sistema."

No nosso exemplo, diante da hipótese de que meu vizinho seja um bom músico, você considerará o que isso significa para mim, que proferi aquela valoraçáo. Isso será feito em relação ao resultado de outras investigações que você realizou - por exemplo, em outras vezes nas quais você ouviu meu

\footnotetext{
${ }^{8}$ Entendo que a abordagem analítica e a abordagem pragmatista, como as estou caracterizando, não sáo estratégias mutuamente excludentes. Entretanto, precisamos levar em conta que os resultados obtidos em cada uma são diferentes. No caso da valoração, a descontextualização analítica parece conduzir ao nâo cognitivismo, o que gera os problemas que apontamos no início do texto.
} 
vizinho tocar, ou em relação a outros músicos que você sabe que considero bons. Além disso, você terá em vista o seu gosto musical (o qual também é objeto de investigação), bem como a sua inclinação para apreciar aquele tipo de música, na ocasião em questão. Todas essas ponderaçôes são operações do raciocínio que levam em conta as potencialidades do curso de ação em relação ao fluxo de experiência. $\mathrm{O}$ resultado desse exame cria uma expectativa que conduz à última etapa da investigação, que é o teste operacional da hipótese escolhida.

Assim, supondo que você ponderou todos esses aspectos da hipótese "meu vizinho é um bom músico" e entendeu que ela apresenta um curso de ação tal que atender ao meu convite e ir ao recital é uma boa solução para a situação indeterminada, a realização da ação conclui a investigação. Se você vai ao recital e presencia uma performance que não só é impecável, de acordo com a noção de boa música que você assumiu, como também é agradável, segundo seus padróes de gosto e suas inclinaçôes na ocasião, então você tem uma confirmação ou verificação da hipótese. ${ }^{9}$ Isto é, você traduz a hipótese valorativa em predições (o segundo tipo de valoração, como apresentamos acima) e obtém experiências diretas de valoração (do primeiro tipo, conforme a proposta de Lewis). Podemos dizer que o teste operacional da hipótese teve resultado favorável, quando essas prediçóes e ocorrências na experiência estáo em harmonia com a hipótese em questáo. Da mesma forma, se você for ao recital e presenciar uma performance ruim ou desagradável, a investigação será concluída com resultado desfavorável à hipótese - e você levará isso em conta, em investigaçóes futuras, tanto a respeito de seu próprio gosto musical quanto a propósito dos convites e valoraçóes que faço, bem como à atribuição de valor à habilidade musical de meu vizinho.

\subsection{VERDAde E JUSTIFICAÇão Na INVESTIGaÇão}

De acordo com a investigação realizada, no caso favorável, você pode considerar que sabe que meu vizinho é um bom músico, porque a sua crença, expressa naquela hipótese, se revelou um bom guia para a ação. Esse é o conceito pragmatista de verdade como uma continuidade em relaçáo ao fluxo

\footnotetext{
${ }^{9}$ Lewis concebe a verificação como um processo que envolve dois momentos no fluxo de experiência: um no qual uma hipótese é levantada e outro no qual se nota que a hipótese é satisfeita. O conhecimento, por ser dependente da verificação, também se estende entre dois momentos, no fluxo de experiência. Lewis desenvolve sua epistemologia em Mind and the World-Order (LEWIS, 1958).
} 
de experiência. ${ }^{10} \mathrm{E}$, mais do que isso, a sua crença não apenas é verdadeira, como também é justificada pela investigação realizada, ou seja, pelo processo de raciocínio ao qual a hipótese foi submetida. Caso você tivesse, logo após o levantamento da hipótese de que meu vizinho é um bom músico, decidido ir ao recital sem ponderar a respeito, a sua crença não poderia ser considerada justificada, pois uma etapa importante da investigação teria sido suprimida. Numa tal situação, frisa Dewey (2008, p. 115), "[...] a conclusão alcançada não está fundamentada, mesmo que aconteça de estar correta."

Nessa perspectiva, também a hipótese "todos os corvos são pretos" só pode ser considerada conhecimento se colocada em um contexto de investigação, isto é, se tomada como sugestão de um curso de ação ponderada em resposta a um problema. A afirmaçáo "todos os corvos são pretos", enquanto crença que possuo, é uma sugestão de cursos de ação que posso adotar, em uma variedade de contextos: posso agir de modo a imaginar uma ave preta, ao ler o poema The Raven, de Edgar Allan Poe; posso sugerir uma visita ao zoológico, a fim de ver os corvos, se você disser que gostaria de ver aves que são inteiramente pretas; posso descartar a possibilidade de serem corvos as aves azuis que vejo, ao caminhar pelo campus. A verdade da hipótese será notada em seu sucesso, em contextos como esses, mas não inteiramente: a hipótese de que todos os corvos sáo pretos tem um significado muito mais amplo do que simplesmente um número finito de instâncias de verificação que obtenho. E a justificação, como no outro caso, vem de uma consideração sobre a confiabilidade do próprio processo investigativo pelo qual cheguei a sustentar a crença como um possível curso de açáo bem-sucedido. No caso dos corvos, a justificação vem da confiança que tenho nas fontes das minhas informaçóes sobre corvos, as quais não são infalíveis, embora possam ser aperfeiçoadas e melhoradas.

A saída pragmatista para a provocação de Russell sobre a participação de Trotsky na Revolução Russa, desse modo, é notar que a etapa de raciocínio ou argumentação - fundamental para a investigação - está sendo impedida por um governo autoritário que cerceia o acesso à informação. Assim, embora possamos ter uma crença, isto é, um curso de ação determinado e bemsucedido como resposta a um problema, não podemos garantir que temos justificação, pois a investigação é impedida. Essa abordagem contempla a

\footnotetext{
${ }^{10}$ A compreensão pragmatista da verdade é comumente associada à máxima pragmática de Peirce, segundo a qual nossa concepção de um objeto é identificada com a nossa concepção das repercussôes práticas de tal objeto (PEIRCE, 1992, p. 132). Para um estudo aprofundado da relação entre a verdade e a máxima pragmática, cf. Hookway (2016).
} 
situação comumente vivenciada em que não sabemos de antemão qual é a verdade que estamos procurando; em situaçóes assim, o apelo que podemos fazer é em relação à confiabilidade do nosso processo de investigar. Uma pessoa que acreditava, em 1920, que Trotsky tinha tido um papel decisivo na Revolução Russa e que foi forçada pela polícia soviética a mudar de opinião, em 1930, não pode dizer que sabe qual foi o papel desempenhado por Trotsky naquele evento - e não porque não pode acessar os fatos relevantes, mas porque não tem condiçóes de investigar adequadamente. Mesmo hoje em dia, não podemos assegurar que temos acesso aos fatos que permitiriam uma crença correspondente à verdade dessa questáo, porém, apenas podemos investigar a respeito - podemos reunir nossos melhores esforços para determinar um curso de ação bem-sucedido. ${ }^{11}$

\section{CONSIDERAÇÕES FINAIS: CONHECIMENTO SOBRE DISTOPIAS}

Vimos, neste texto, que Russell argumenta de maneira razoável que não podemos ter conhecimento sobre valoraçôes, pois tais reflexôes não adquirem um caráter objetivo. Vimos também que essa conclusão de Russell contraria uma noçáo comum, a de que adquirimos conhecimento, quando refletimos sobre valores. Russell parece preferir deixar de lado essa noçáo comum, bem como sua própria filosofia social, para sustentar uma compreensão da verdade como correspondência. Em outras palavras, Russell está comprometido com uma distinção entre fatos e valores, a qual traz complicações para suas próprias ideias sobre a sociedade. Como alternativa a esse dilema, vimos a teoria da valoração de Lewis, a qual apresenta a objetividade de juízos valorativos em continuidade com a objetividade de juízos factuais. Ao associar essa teoria da valoração à teoria da investigação da Dewey, mostramos que é possível conceber as reflexôes sobre valores em processos investigativos, os quais, quando bem-sucedidos, culminam em verdade e justificação.

Dessa forma, retomando a questão do estatuto epistêmico da filosofia social de Russell e da distopia de Huxley, podemos salvar a noção comum de que obtemos conhecimento a partir dessas obras e discussóes, pois estamos

\footnotetext{
${ }^{11}$ Podemos levantar a questão de que a abordagem pragmatista pressupóe uma ordem social democrática que náo impeça a investigação. De fato, Dewey entende a ciência e a democracia como duas instituiçôes que sustentam uma à outra (cf. DEWEY, 2008; cf. também FESTENSTEIN, 2018). Assim, podemos conceber a sociedade democrática em um esforço contínuo de investigação, no qual aprendemos com as experiências do passado, desenvolvendo uma razão valorativa que evolui, ao longo da história. Discutir essa questão de maneira pormenorizada foge aos objetivos do presente texto.
} 
diante de resultados de investigaçôes. Ou seja, Russell, assim como Huxley e outros autores de filosofia social e da tradição utópica e distópica, estava realizando investigaçóes sobre como poderia ser uma sociedade ideal ou, de maneira mais precisa, sobre o funcionamento de certos arranjos sociais. ${ }^{12}$ Vejamos como descrever o contexto dessas investigaçóes.

Podemos considerar que a situação indeterminada de dúvida que antecede a investigaçáo é a de não compreender completamente a relevância de avanços científicos e tecnológicos e de não ter um posicionamento definido a respeito deles. O sentimento de confusão que acompanha essa situação é familiar para quem vive no mundo contemporâneo, e é razoável supor que Russell e Huxley já passavam por isso, no início do século XX. Nesse caso, a formulação do problema, que motiva a investigação, envolve identificar quais são os avanços científicos e tecnológicos, que, se implementados, terão consequências sobre a vida individual e social. Além disso, o problema leva em conta o contexto em que tais avanços técnicos podem ser usados. No caso que estamos tomando como exemplo, tanto Huxley quanto Russell identificam que a engenharia genética, as drogas psicoativas e as técnicas de controle psicológico podem ser usadas para atender ao interesse de quem detém o poder ou o controle do capital.

Dessa forma, as hipóteses que são levantadas dizem respeito a consequências dessas técnicas e tecnologias no contexto indicado. Assim, podemos cogitar que uma estrutura de castas pode surgir; podemos aventar a perda de direitos trabalhistas, numa tal sociedade; podemos projetar um aumento na liberdade sexual, já que a reprodução será feita apenas em laboratório; podemos imaginar as consequências disso, na arte e na filosofia e também na prática científica. Essas consequências podem ser consideradas factuais, e tanto Russell quanto Huxley as apresentam junto a muitas outras. Mas, em meio a essas hipóteses, podem surgir hipóteses valorativas, de que certas consequências serão agradáveis ou desagradáveis, boas ou ruins, justas

$\underline{12}$ A tradição de discussão sobre valores geralmente toma conceitos bastante abstratos, como os fins da ação humana. Isso entra em conflito com a abordagem que este artigo está desenvolvendo, pois contextos de investigação surgem de situaçóes indeterminadas vivenciadas e oferecem soluçôes localizadas. Isto é, podemos encontrar o melhor arranjo social (ou descartar algum que seja ruim) para certa situação vivenciada por uma comunidade; contudo, não temos condiçôes de investigar sobre como é a sociedade ideal em geral. De modo análogo, nossas investigaçôes podem apontar para o que seria, por exemplo, uma solução justa a um dado problema, mas não teríamos condiçôes de constituir um contexto para investigar sobre o que é a justiça. Isso é discutido de maneira mais profunda por Dewey (1970). Em contextos de investigaçáo, devemos considerar a valoração em termos de meios e de fins que temos em vista - e nunca em relação a fins absolutos, extrínsecos às situaçōes vivenciadas. 
ou injustas. Essas hipóteses surgem na própria experiência de leitura. ${ }^{13} \mathrm{E}$ o raciocínio que desenvolvemos, a partir de cada uma das hipóteses, será também factual e valorativo. Huxley aproveita-se disso, em sua obra, ao desenvolver os valores adotados por seus personagens, conduzindo o leitor a raciocinar sobre seus próprios valores. Russell, por outro lado, adota sua postura objetivista, mantendo-se mais próximo às consequências factuais obtidas das hipóteses sobre questóes de fato.

Em função do desdobramento das hipóteses nos termos do problema formulado, chegamos à etapa final da investigação, o teste. Russell e Huxley elaboram posicionamentos sobre as consequências dos avanços tecnológicos, os quais, na perspectiva pragmatista, se traduzem em cursos de ação que terão a potencialidade de nos conduzir a experiências valorativas do primeiro tipo, isto é, a percepçôes de qualidades valorativas. Isso não é tão claro na obra de Russell, uma vez que, tendo insistido ao longo do livro em discussóes factuais, ele se resume nos capítulos finais a apresentar sua visão de que o conhecimento sem sabedoria pode ter consequências desastrosas: "[...] o homem embriagado de poder é destituído de sabedoria, e enquanto ele governar o mundo, o mundo será um lugar desprovido de beleza e de alegria” (RUSSELL, 2009, p.194). Já Huxley, em sua estratégia literária, apresenta a percepção de qualidades valorativas por parte de seus personagens, diante dos desdobramentos da narrativa. Tal valoração é distópica, já que seus personagens, com os quais os leitores vão se identificando ao longo do livro, acabam por ser marginalizados ou exilados. Mas Huxley observa que essa valoração não é necessária e universal, visto que um de seus personagens, o escritor chamado Helmholtz Watson, adota uma postura de resignação, buscando ver o lado bom de seu exílio (HUXLEY 2014, p. 273-274). Ainda assim, não podemos negar que Huxley e Russell, assim como seus leitores, sabem que a sociedade descrita é, em geral, distópica. Isso porque, em primeiro lugar, as investigaçôes feitas pelos autores resultam, por parte dos leitores, na percepção de qualidades valorativas, ou seja, na criação de valoraçôes do primeiro tipo de Lewis. Assim, as hipóteses levantadas, de que os avanços técnicos apresentados teriam consequências ruins, geram, no curso da investigação, propostas de cursos de ação que nos conduzem à percepção de qualidades valorativas primárias. Considerando que obtemos harmonia nesse trecho do fluxo da experiência, podemos atribuir ao resultado da investigação o conceito pragmatista de verdade ou, como prefere Dewey, assertabilidade garantida. Além disso, podemos justificar

${ }^{13} \mathrm{O}$ processo pelo qual essas experiências surgem foi analisado como similar ao processo de criação de efeitos em laboratório, em Cunha (2018). 
essa conclusão com base na confiança que temos nas investigaçóes feitas por Huxley e por Russell e que acompanhamos de perto, ao ler suas obras.

É certo que o grau de justificação que atribuímos pode não ser tão alto assim - pode ser baseado na autoridade desses grandes pensadores. Todavia, podemos sempre investigar mais, considerar os resultados de outras investigaçóes, desenvolver e utilizar outros métodos para raciocinar e argumentar sobre os desdobramentos das hipóteses, propondo cursos de ação e a obtenção de experiências de valoração. É certo, por fim, que podemos tomar as conclusóes de Russell e de Huxley, bem como outras obras de filosofia social e de arte distópica, como conhecimento obtido em investigaçôes passadas a respeito de melhorias na organização social. Como tal, esse conhecimento tem seu domínio restrito ao contexto de investigação que foi instituído naquela ocasião - esse conhecimento é uma resposta a um problema específico, formulado a partir de uma situação de dúvida específica. Não temos a ilusão de produzir conhecimento absoluta e universalmente válido e necessário. $\mathrm{O}$ melhor que podemos fazer é prosseguir na investigação sobre como melhorar nossos arranjos sociais - e, nesse prosseguimento, podemos empregar o conhecimento obtido por Russell e Huxley de maneira heurística, como sugestôes de arranjos que podem ou que não podem dar certo.

Agradecimentos: Este texto se beneficia de discussóes que tive com Alexander Linsbichler, Caroline E. Murr e Tiago Ponti. Agradeço também a três avaliadores(as) anônimos(as), pelos comentários e sugestóes.

CUNHA, I. F. Valores, Verdade e Investigação: uma alternativa pragmatista ao não cognitivismo de Russell. Trans/form/açāo, Marília, v. 43, n. 3, p. 245-268, Jul./Set., 2020.

\footnotetext{
Abstract: This article presents a pragmatist framework to understand the epistemic status of valuations produced upon reflection on social consequences of scientific and technological proposals. The problem is set following Bertrand Russell's considerations on the impact of science on society. Russell argues that valuating social arrangements falls beyond the limits of knowledge, because valuations cannot be true or false in the sense of correspondence. This leads social thought to a deadlock, since one cannot know that a given social arrangement would be undesirable or inadequate. This article sketches an alternative from Clarence Irving Lewis's works on valuation taken in continuity with John Dewey's theory of inquiry. This alternative framework assumes epistemic notions of truth and
} 
justification, allowing that valuations can be construed in contexts of inquiry and thus as objects of knowledge.

Keywords: Epistemology. Social Philosophy. Dystopia. Russell. Pragmatism.

\section{REFERÊNCIAS}

AYER, Alfred Jules. Language, Truth and Logic. London: Penguin, 2001 [1936].

CARNAP, Rudolf. Theoretische Fragen und praktische Entscheidungen. Natur und Geist v.2, n.9, p.257-260, 1934.

CUNHA, Ivan F. da. Utopias and Dystopias as Models of Social Technology. Principia v.19, n.3, p.363-377, 2015.

CUNHA, Ivan F. da. Constructing dystopian experience: a Neurath-Cartwrightian approach to the philosophy of social technology. Studies in History and Philosophy of Science v.72, p.41-48, 2018.

DUTRA, Luiz Henrique de Araújo. Verdade e Investigação. São Paulo: EPU, 2001.

DEWEY, John. Experience and Nature. New York: Dover, 1958 [1929].

DEWEY, John. Theory of Valuation. In: NEURATH, Otto; CARNAP, Rudolf; MORRIS, Charles. (Orgs.). Foundations of the Unity of Science. Volume 2. Chicago: Chicago University Press, 1970 [1939], p.379-447.

DEWEY, John. Democracy and Education. New York: Macmillan, 2008 [1916].

DEWEY, John. Logic: the theory of inquiry. In: BOYDSTON, Jo Ann. (Org.). The Later Works. Volume 12. Carbondale: Southern Illinois University Press, 2008 [1938].

FESTENSTEIN, Matthew. Dewey's Political Philosophy. In: ZALTA, Edward N. (Org.). The Stanford Encyclopedia of Philosophy (Fall 2018), 2018. https://plato.stanford. edu/archives/fall2018/entries/dewey-political/. Acesso: 29.09.2018.

HAACK, Susan. Filosofia das Lógicas. Trad. C. A. Mortari \& L. H. Dutra. São Paulo: Editora UNESP, 2002 [1978].

HOOKWAY, Christopher. Pragmatism. In: ZALTA, Edward N. (Org.). The Stanford Encyclopedia of Philosophy (Summer 2016), 2016. https://plato.stanford.edu/archives/ sum2016/entries/pragmatism/. Acesso: 21.12.2018.

HUXLEY, Aldous. Admirável Mundo Novo. Trad. L. Vallandro \& V. Serrano. São Paulo: Globo, 2014 [1932].

JAMES, William. Essays in Radical Empiricism. New York: Dover, 2003 [1912].

LE GUIN, Ursula K. Os Despossuídos. Trad. S. L. de Alexandria. São Paulo: Aleph, 2017 [1974]. 
LEWIS, Clarence Irving. An Analysis of Knowledge and Valuation. La Salle: Open Court, 1946.

LEWIS, Clarence Irving. Mind and the World-Order. New York: Dover, 1956 [1929].

LEWIS, Clarence Irving. Experience and Meaning. In: GOHEEN, John D.;

MOTHERSHEAD JR., John L. (Orgs.). The Collected Papers of Clarence Irving Lewis. Stanford: Stanford University Press, 1970 [1934], p.258-76.

ORWELL, George. 1984. Trad. W. Velloso. São Paulo: Companhia Editora Nacional, 2000 [1949].

PEIRCE, Charles Sanders. The Fixation of Belief. In: HOUSER, Nathan; KLOESEL, Christian (Orgs.). The Essential Peirce. Volume 1. Bloomington: Indiana University Press, 1992 [1877], p.109-123.

PEIRCE, Charles Sanders. How to Make Our Ideas Clear. In: HOUSER, Nathan; KLOESEL, Christian (Orgs.). The Essential Peirce. Volume 1. Bloomington: Indiana University Press, 1992 [1878], p.124-141.

PIGDEN, Charles R. Bertrand Russell: Moral Philosopher or Unphilosophical Moralist?. In: GRIFFIN, Nicholas. (Org.). The Cambridge Companion to Russell. Cambridge: Cambridge University Press, 2003, p.475-506.

ROSENTHAL, Sandra B. C. I. Lewis in Focus: the pulse of pragmatism. Bloomington and Indianapolis: Indiana University Press, 2007.

RUSSELL, Bertrand. Marriage and Morals. New York: Liveright, 1970 [1929].

RUSSELL, Bertrand. The Impact of Science on Society. New York: Routledge, 1985 [1952].

RUSSELL, Bertrand. Theory of Knowledge: the 1913 manuscript. New York: Routledge, 1992 [1984].

RUSSELL, Bertrand. Philosophical Essays. New York: Routledge, 1994 [1910].

RUSSELL, Bertrand. The Philosophy of Logical Atomism. Chicago: Open Court, 1998 [1918].

RUSSELL, Bertrand. The Analysis of Matter. Nottingham: Spokesman, 2007 [1927].

RUSSELL, Bertrand. The Scientific Outlook. New York: Routledge, 2009 [1931].

RUSSELL, Bertrand. Education and Social Order. New York: Routledge, 2010 [1932].

RUSSELL, Bertrand. História da Filosofia Ocidental. 3 Volumes. Trad. H. Langone. Rio de Janeiro: Nova Fronteira, 2015 [1945].

SÁNCHEZ GARCÍA, Victoria Paz. A Review of Morton White’s Criticisms Concerning Clarence Irving Lewis' Theory of Valuation and Normativity. Cognitio v.18, n.2, p.259272, 2017. 
CUNHA, I. F.

VAN ROOJEN, Mark. Moral Cognitivism vs. Non-Cognitivism. In: ZALTA, Edward N. (Org.). The Stanford Encyclopedia of Philosophy (Fall 2018), 2018. https://plato. stanford.edu/archives/fall2018/entries/moral-cognitivism/. Acesso: 03.09.2018.

ZAMYATIN, Yevgeny. Nós. Trad. G. Soares. São Paulo: Aleph, 2017 [1924].

Recebido: 17/01/2019

Aceito: 24/02/2020 